\title{
Personal Aspirations, THE "GOOD LIFE” AND THE LAW
}

\author{
TIM KASSER
}

\begin{abstract}
[Many of the messages conveyed and laws created by capitalistic, consumer culture encourage the pursuit of goals for wealth, image and status. Substantial research shows, however, that when individuals focus on such "extrinsic" goals, they report lower personal well-being and engage in more problematic social and ecological behaviour than when they are oriented towards "intrinsic" pursuits for personal growth, affiliation, and community feeling. Legislative agendas that are designed to increase "time affluence" and protect children from commercialisation are discussed as example activities lawyers could pursue to help increase intrinsic and decrease extrinsic aspirations.]
\end{abstract}

\section{INTRODUCTION}

Consider a man who aspires to make a great deal of money. By placing a great deal of emphasis on this particular aim in life, this man is likely to create a lifestyle for himself in which he works long hours, to chose a profession based more on its pay and status than on its inner rewards, and to make decisions that maximise his own personal material gain when confronted with certain quandaries. Such experiences and decisions, in turn, have ramifications for his own personal quality of life and for the well-being of those around the man. For example, if this man works 80 hour weeks with rare vacations, little time is left to pursue enjoyable activities, to nurture relationships with his spouse and children, or to use his skills and talents to contribute to his community. As a result of this choice of values and goals, the well-being of the man, his family, and his community may all suffer.

\footnotetext{
${ }^{*}$ Associate Professor of Psychology, Knox College, Galesburg, Illinois, USA.
} 
Over the last decade, my colleagues and I have been scientifically studying aspirations such as the desire for wealth as a way of understanding whether the different values and goals that people hold relate in systematic ways to their own quality of life, as well as to the well-being of others. As hinted at above, we believe that aspirations are a useful way to understand "the good life," because such values and goals influence the kinds of experiences individuals have and the decisions they make in life. These experiences and decisions, in turn, affect people's well-being and happiness. In addition, we find values, goals and aspirations useful and interesting to study because they are influenced by the manifold messages people receive from others in the social surround about what particular pathways might lead towards a specific conception of "the good life." As such, the study of values and goals provides an inroad for understanding how cultural practices and institutions (including laws) might facilitate or hinder citizens' pursuit of "the good life," and offers the opportunity to make practical suggestions about changes that might be made to such practices and institutions.

\section{INTRINSIC AND EXTRINSIC ASPIRATIONS}

Although researchers have studied a variety of issues concerning values and goals throughout the years, my colleagues and I have been especially interested in the content of people's aspirations. That is, we are interested in the ramifications of caring about and pursuing goals like "helping the world be a better place" and "knowing myself in a deep and full way" as opposed to "becoming wealthy" or "being well-known and admired." The basic distinction with regard to goal content that we have made in our research has been between what we call "intrinsic" and "extrinsic" pursuits ${ }^{1}$

Intrinsic goals are those that are inherently satisfying to pursue because they tend, on average, to be congruent with important psychological needs held in common by all people. ${ }^{2}$ There are three main intrinsic goals that we have studied. Personal growth goals concern strivings to more deeply understand one's own self and to pursue one's own interests and callings. Affiliation goals involve being closely connected to family and friends. Community feeling goals are primarily about trying to improve the state of the broader world through activism. As most readers likely recognise, these three intrinsic goals have traditionally been encouraged by various philosophical and religious traditions as important pursuits that are purported to bring happiness.

Extrinsic goals differ from intrinsic goals in that they are focused on obtaining external rewards and praise, and in that they are typically means to some other end. As such, they are generally not satisfying in and of themselves and can often dis-

\footnotetext{
${ }^{1}$ Tim Kasser et. al., Further Examining the American Dream: differential correlates of intrinsic and extrinsic goals, 22 PERSONALITY S. P. B, 280-287 (1996).

${ }^{2}$ Tim Kasser, Sketches for a self-determination theory of values, in HANDBOOK OF SELFDETERMINATION RESEARCH 123-140 (Edward. L. Deci \& Richard. M. Ryan eds., (2002)). See also: Richard M. Ryan, \& Edward. L, Deci, Self-determination theory and the facilitation of intrinsic motivation, social development, and well-being, 55 AMERICAN P., 68 -78 (2000).
} 
tract from satisfaction of one's psychological needs. We have typically studied three main extrinsic goals. Financial success goals concern making a lot of money and having many nice possessions. Image goals involve having an attractive physical appearance and being "in style." Popularity aspirations are to be well-known and admired and to have high status among others. Extrinsic goals are also wellemphasised by some socialising agencies, particularly those involved in attempts to convince individuals that the path to happiness is best pursued through consumption of goods and services that bolster a nation's Gross National Product.

This theoretical distinction between intrinsic and extrinsic goals has substantial research support. Statistical analyses show that when people are given scales that measure the importance they place on different types of goals, intrinsic and extrinsic goals separate themselves into distinct factors. This result has been replicated cross-culturally in the United States, ${ }^{3}$ Germany, ${ }^{4}$ South Korea, ${ }^{5}$ and Russia, ${ }^{6}$ and has occurred in both college students and adults. More recently, we have used the advanced statistical techniques of multi-dimensional scaling and circular stochastic modelling in a sample of over 1850 college students from 15 nations around the world (including Australia) to show that intrinsic and extrinsic goals are distinguishable aspirations which oppose each other.

The distinction between intrinsic and extrinsic aspirations garners its strongest support from the variety of studies showing that the two types of goals relate differently to quality of life. In most of these studies, individuals are presented with a scale that asks them to rate the importance of a variety of different goals and values, ${ }^{8}$ or to tell the researchers the strivings or personal projects that they are pursuing these days. ${ }^{9}$ These measures are used to assess the relative importance or centrality ${ }^{10}$ that people place on different types of goals; through this means, researchers can know for particular study participants where intrinsic and extrinsic aspirations stand in the pantheon of aims one might pursue in life. Table 1 gives

\footnotetext{
${ }^{3}$ Kasser \& Ryan, supra note 1, at 280-287.

${ }^{4}$ Peter Schmuck, Tim Kasser \& Richard M. Ryan, Intrinsic and extrinsic goals: Their structure and relationship to well-being in German and U.S. college students, 50 SOCIAL I. R., 225- 241 (2000).

${ }^{5}$ Youngmee Kim, et. al, Self-concept, aspirations and well-being in South Korea and the United States, 143 JOURNAL S. P., 277-290 (2001).

${ }^{6}$ Richard. M. Ryan, et. al., The American dream in Russia: Extrinsic aspirations and well being in two cultures, 26 PERSONALITY S. P. B, 1509-1524 (1999).

${ }^{7}$ Frederick M. E. Grouzet, et. al, The Structure of Goal Contents Across 15 Cultures (2005) (Unpublished manuscript, submitted for publication)

${ }^{8}$ Tim Kasser \& Richard M. Ryan, A dark side of the American Dream: Correlates of Financial Success as a Central Life Aspiration, 65 Journal P. S. P, 410-422 (1993); Tim Kasser \& Richard M. Ryan, Be careful what you with for: Optimal functioning and the relative attainment of intrinsic and extrinsic goals, in LIFE GOALS AND WELL-BEING: TOWARDS A POSITIVE PSYCHOLOGY OF HUMAN STRIVING, 116131 (Peter Schmuck et. al., eds., 2001).

${ }^{9}$ Kennon M. Sheldon \& Tim Kasser, Coherence and Congruence: Two aspects of personality integration, 68 Journal P. S. P., 531-543 (1995); Kennon M. Sheldon \& Tim Kasser, Pursing Personal goals: Skills enable progress, but not all progress is beneficial, 24 PERSONALITY S. P. B., 1319- 1331 (1998). Kennon M. Sheldon \& Tim Kasser, "Getting older, Getting better": Personal strivings and psychological maturity across the life span, 37 DEVELOPMENTAL P., 491 -501, (2001).

${ }^{10}$ Milton Rokeach, The Nature of Human Values (1973).
} 
sample items of intrinsic and extrinsic goals from one of the most common measures that we use, the Aspiration Index. ${ }^{11}$

\section{Table 1}

Sample intrinsic and extrinsic items from the Aspiration Index (from Grouzet et al., 2005).

\begin{tabular}{|l|l|}
\hline Aspiration Type & \multicolumn{1}{|c|}{ Sample Item } \\
\hline Personal Growth & I will have insight into why I do the things I do. \\
\hline Affiliation & I will have a committed, intimate relationship. \\
\hline Community Feeling & I will help the world become a better place. \\
\hline Financial Success & I will have many expensive possessions. \\
\hline Image & I will achieve the "look" I've been after. \\
\hline Popularity & I will be admired by many people. \\
\hline
\end{tabular}

Note: Participants are asked to rate the importance of each item on a scale ranging

from " $1=$ not at all important" to " $9=$ extremely important."

Space constraints preclude a lengthy review of the relevant research and of a theoretical explanation for the results of these studies; readers interested in a fuller exposition are referred some of my other writings. ${ }^{12}$ Hopefully, however, the summary below will provide readers with a sense that intrinsic and extrinsic pursuits have different ramifications for "the good life" and that it would be worthwhile to consider how laws and legal practices might better facilitate intrinsic and discourage extrinsic pursuits.

\footnotetext{
${ }^{11}$ Kasser \& Ryan, supra note 8, at 410 -422; Kasser \& Ryan, supra note 1, at 280-287; Kasser \& Ryan, supra note 8 , at $116-131$.

${ }^{12}$ Kasser, supra note 2 .
} 


\section{A Personal well-being}

A growing number of studies document that when people organise their lives around intrinsic aspirations for personal growth, affiliation, and community feeling, their subjective well-being and happiness is enhanced, whereas when the extrinsic pursuits of money, image, and status are relatively important, people actually report lower well-being. Such results go beyond the typical adage that "Money can't buy happiness" (which is well-supported, by the way ${ }^{13}$ ) and show that when individuals "buy into" the materialistic messages spread by consumeristic, capitalistic societies, they actually report lower well-being. This conclusion is supported by research examining a variety of indices of well-being in several distinct types of samples of individuals.

For instance, studies show that when people's goal systems have a heavy dose of extrinsic goals and a lowered focus on intrinsic pursuits, they report less happiness, less satisfaction with life, a lower sense of vitality, lower self-actualisation, fewer experiences of day-to-day pleasant emotions, and lower overall functioning in life. ${ }^{14}$ Extrinsic aspirations not only diminish happiness, but also conduce towards greater levels of unhappiness and psychopathology. For example, studies show that more extrinsically and less intrinsically-oriented people report more depression, more anxiety, more conduct disorders, more personality disorders, more substance abuse problems, more narcissism, more physical health symptoms, and more experiences of unpleasant emotions. ${ }^{15}$ Importantly, this panoply of psychological problems associated with an extrinsic orientation towards life has been documented by a variety of researchers. ${ }^{16}$

Results demonstrating the negative well-being ramifications of extrinsic goals and the positive effects of intrinsic goals have also been documented in a variety of samples. First, with regard to age, the findings have been documented in early adolescents, ${ }^{17}$ college students, ${ }^{18}$ and adults. ${ }^{19}$ Second, strong extrinsic aspirations are associated with lower well-being even in samples of individuals who live in environments which generally support and encourage the pursuit of profit, such as business students, ${ }^{20}$ entrepreneurs, ${ }^{21}$ and lawyers. ${ }^{22}$ Third, the differential well-being

\footnotetext{
${ }^{13}$ Ed Diener \& Martin Seligman, Beyond Money: Toward an economy of well being, 5 PSYCHOLOGICAL S. P. I, 1 - 31 (2004)

${ }_{14}$ See Tim KASSER, THE High PRiCE OF MATERIALISM (2002)

${ }^{15} I d$.

${ }^{16}$ Russell Belk, Materialism: Trait aspects of living in the material world, 12, JOURNAL C. R. $265-280$, (1984); Marsha L. Richins, et. al., A consumer values orientation for materialism and its measurement: Scale development and validation, 19 JOURNAL C. R., 303-316 (1992); PATRICIA COHEN \& JACOB COHEN, Life VAlues AND AdOLESCEnt MENTAL HeAlth, (1996); Emily Solberg, et. al., Why are materialists less satisfied?, in PSYCHOLOGY AND CONSUMER CUlTURE: THE STRUGGLE FOR A GOOD LIFE IN A MATERIALISTIC WORLD 29- 48 (Tim Kasser \& Allen Kanner eds., 2004).

${ }^{17}$ COHEN \& COHEN, supra note 16.

${ }^{18}$ Kasser \& Ryan, supra note 8, at 410-422; Kasser \& Ryan, supra note 1, at 280-287; Kasser \& Ryan, supra note 8 , at $116-131$.

${ }^{19}$ Kasser \& Ryan, supra note 1, at 280-287, Sheldon \& Kasser, supra note 9 at 491-501.

${ }^{20}$ Tim Kasser, et. al., Materialistic values and well-being in business students, 32 EUROPEAN J. S. P., 137-146 (2002).
} 
correlates of intrinsic and extrinsic goals have been replicated in a variety of cultures, including Australia, ${ }^{23}$ Britain, ${ }^{24}$ Belgium, ${ }^{25}$ Denmark, India, ${ }^{26}$ Germany, ${ }^{27}$ Romania, ${ }^{28}$ Russia, $^{29}$ Singapore $^{30}$ and South Korea. ${ }^{31}$

In sum, then, the research literature clearly demonstrates that when people organise their lives around the pursuit of extrinsic goals for money, image, and status, their personal well-being is lessened. Such findings are in direct contradiction to the promises held out by modern-day consumer, capitalistic culture. Instead, the bulk of the literature supports the idea that "a good life" results when individuals focus on their own personal growth, when they share their lives with people they love, and when they work to make the world a better place.

\section{B Social Justice}

If our goal is to maximise the personal well-being of as many people as possible, there are other reasons to attempt to create conditions that encourage intrinsic and discourage extrinsic aspirations. Recent research demonstrates that individuals who focus on extrinsic goals and values express attitudes and act in ways which are likely to interfere with other people's attempts to be happy and live "a good life." In contrast, intrinsically oriented individuals generally are more supportive of others' attempts to be happy and well.

To begin, substantial research shows that when individuals focus on extrinsically oriented goals, they tend to place less emphasis on intrinsically oriented goals such as affiliation and community feeling. As mentioned above, Grouzet et al. ${ }^{32}$ showed that, in each of the 15 nations studied, intrinsic and extrinsic goals opposed each other. Similar results have been reported by Cohen \& Cohen $^{33}$ and by Schwartz ${ }^{34}$

MaarteenVansteenkiste, et. al., Materialistic values and well-being among business students: Further evidence for their detrimental effect, JOURNAL A. P. S. P. (in press).

${ }^{21}$ Atima Srivastava, et. al., Money and Subjective well-being: It's not the money, it's the motives, 80 JOURNAL P.S.P, 959-971 (2001).

${ }^{22}$ Kennon M. Sheldon, et. al., Does Law School Undermine Law Students? Examining Changes in Goals, Values and Well-being, 22 BEHAVIOURAL S. L., 261-282, (2004).

${ }^{23}$ Shaun Saunders, et. al., The construction and validation of a consumer orientation questionnaire (SCO1) designed to measure Fromm's (1955) 'marketing character' in Australia, 28, SocIAL B. P. 219 240 (2000).

${ }^{24}$ Raymond Chan, et. al., Dimensions of personality, domains of aspiration, and subjective well-being, 28 PERSONALITY I. D. 347 -354, (2000).

${ }^{25}$ Vansteenkiste, et. al, supra note 20 (in press).

${ }^{26}$ Shiviani Khanna, Corrosive messages and capitalist ideology: Well-being, objectification, and alienation from a cross-cultural perspective (1999) (unpublished Honours Thesis, Knox College, Galesburg, IL).

${ }^{27}$ Schmuck, Kasser \& Ryan, supra note 4 at 225-241.

${ }^{28}$ Kate M Frost, A cross-cultural study of major life aspirations and psychological well being (1998)

(unpublished doctoral dissertation, University of Texas at Austin).

${ }^{29}$ Ryan et. al., supra note 6, at 1509-1524.

${ }^{30}$ Kasser, et. al., supra note 20 at 137- 146.

${ }^{31}$ Youngmee Kim, et. al., Self-concept, aspirations, and well-being in South Korea and the United States, 143 JOURNAL S. P., 277-290 (2003).

${ }^{32}$ Grouzet, et. al, supra note 7.

${ }^{33}$ COHEN \& COHEN, supra note 16. 
with regard to people's values and priorities in life. What this means, then, is that to the extent individuals care about making a great deal of money, having the right image, and achieving status, they tend to care less about being close to others, about equality, and about helping the world be a better place. These data help make it understandable why certain corporate executives, in their compulsion to make everlarger amounts of money, can often ignore their families, bilk investors and consumers, and leave communities bereft when they lay off workers in their attempts to maximise profits. When extrinsic aspirations for money and wealth become dominant, intrinsic concerns to help others are lessened and choices are made that have dramatic impacts on other people's lives and well-being.

Other research shows that the interpersonal styles of individuals with strong extrinsic values are not likely to conduce to the well-being of others. Studies shows, for example, that extrinsically oriented individuals are more likely to report engaging in anti-social acts ${ }^{35}$ and less likely to engage in pro-social activities that involve helping others and sharing. ${ }^{36}$ Further, extrinsically oriented individuals are less empathic, ${ }^{37}$ and thus spend less effort trying to see the world from another person's point of view. Their tendency towards manipulativeness of others is demonstrated in research showing that extrinsically oriented individuals tend to identify with a Machiavellian philosophy ${ }^{38}$ and are more competitive and less cooperative when placed in social dilemmas. ${ }^{39}$ Together, these results suggest that the goals which organise the lives of extrinsically oriented individuals lead them to make choices that maximise their own personal gain and to care little about the welfare of others. In contrast, the goals of intrinsically oriented individuals lead them to act in ways that express more care about how their behaviour influences the well-being of others around them.

\section{Ecological sustainability}

Maximising the well-being of one's self and of other people in one's social surround, in my mind, is still not a complete definition of "a good life." We humans are part of a broader living world that extends to other species and involves future generations yet to be born. As such, "a good life" must also take into consideration how our actions affect the broader ecology, on which the well-being of redwood trees, whooping cranes, Siberian tigers and our great-great grandchildren ultimately depends. And, once again, the research shows that whereas intrinsic values and

\footnotetext{
${ }^{34}$ Shalom H. Schwartz, Universals in the content and structure of values: theory and empirical tests in 20 countries, in ADVANCES IN EXPERIMENTAL SOCIAL PSYCHOLOGY 1-65, (Mark Zanner ed.), (1992). ${ }^{35}$ COHEN \& COHEN, supra note 15, Kasser \& Ryan, supra note 8, 410-422 and John W. McHoskey, Machiavellianism, intrinsic versus extrinsic goals, and social interest: A self-determination theory analysis, 23, MOTIVATION E. 267 -283, (1999).

${ }^{36}$ Tim Kasser, Frugality, generosity and materialism in children and adolescents, in CONCEPTUALIZING AND MEASURING INDICATORS OF POSITIVE DEVELOPMENT: WHAT DO CHILDREN NEED TO FLOURISH? 358-374 (K. Moore \& L. Lippman eds., 2005); McHoskey, supra note 35 at 267 -283; Sheldon \& Kasser, supra note 9 at $531-543$.

${ }^{39}$ Kennon M. Sheldon, et. al., Prosocial values and group assortation in an N-person prisoner's dilemma, 11 HUMAN N. 387 - 404 (2000).
} 
goals tend to support ecological well-being and sustainability, extrinsic values and goals are associated with attitudes and behaviours that undermine this facet of a good life.

Just as the research shows that extrinsic goals and values are associated with caring less about others, other studies show that such pursuits also interfere with caring about the ecology of the world at large. Cross-cultural research shows that when people value financial success, they are less concerned with attaining "a world of beauty" or "unity with nature," and care less about "protecting the environment". ${ }^{40}$ Similarly, Saunders \& Munro found that materialistic individuals score lower in "biophilia," or love of living things. ${ }^{41}$

Other research shows that when people have an extrinsic, materialistic orientation towards life, they are less likely to engage in relatively simple behaviours that can benefit the ecology, like riding a bike, recycling, or using less water. Such findings have been documented in adult samples in Australia ${ }^{42}$ and the United States, ${ }^{43}$ as well as in US adolescents. ${ }^{44}$ What's more, studies demonstrate that extrinsically oriented individuals behave in ways that involve the use of more ecological resources. When asked to play social dilemma games that involve the opportunity to harvest timber from a national forest, extrinsically oriented individuals report more feelings of greed and also bid to harvest more timber than do intrinsically oriented individuals. ${ }^{45}$ And Brown \& Kasser $^{46}$ found that, compared to intrinsically oriented adults, the lifestyles of extrinsically oriented individuals have higher ecological footprints, ${ }^{47}$ due to their food, housing, and transportation choices. ${ }^{48}$

Many scientists recognise that the consumption patterns typical of economically developed nations such as the United States and Australia are unsustainable, and thus worry that the costs of our current lifestyle in terms of eventual human suffering will be quite high. ${ }^{49}$ The data presented above suggest that the aspirations that individuals hold are implicated in such consumption patterns and that a shift away from extrinsic and towards intrinsic pursuits may be necessary in order to help maintain the possibility of "a good life" on Earth.

\footnotetext{
${ }^{40}$ Schwartz, supra note 34 at 1-65.

${ }^{41}$ Saunders, et. al., supra note 23 at 219-240.

${ }^{42} I d$.

${ }^{43}$ K W Brown \& Tim Kasser, et. al., Are Psychological and Ecological Well-Being Compatible? The Roles of Values, Mindfulness and Lifestyle (2004) (in press)); Richins, supra note 16, 303-316.

${ }^{44}$ Tim Kasser \& K M Sheldon, Of wealth and death: Materialism, mortality salience, and consumption behavior, 11 PSYCHOLOGICAL SCIENCE 352-355 (2000).

${ }^{45}$ Sheldon \& Kasser, supra note 9 at 491 -501; Kennon M. Sheldon \& Holly McGregor, Extrinsic Value

Orientation and the tragedy of the commons, 68 JOURNAL P. 383-411 (2000).

${ }^{46}$ Brown \& Kasser, supra above n 43.

${ }^{47}$ Ritik Dholakia \& Mathis Wackernagel, The Ecological Footprint Questionnaire San Francisco, CA: Redefining Process (1999).

${ }^{48}$ Brown \& Kasser, supra note 43.

${ }^{49}$ Union of Concerned Scientists, World scientist's warning to humanity [Pamphlet]. Available from Union of Concerned Scientists, 2 Brattle Square, Cambridge, MA 02238, (617) 547-5552, (1992).
} 


\section{LEgISLATIVE AgENDAS}

Having summarised some of the research evidence concerning how intrinsic and extrinsic aspirations relate to "the good life", I turn now to applying this frame of reference to legal issues. My lack of training in things legal leads me to present these ideas with some trepidation, as I run the risk of appearing naïve on the one hand or overly bold on the other. Certainly my readers have a much better conception than I of how the legal profession operates and the day-to-day realities that might be explained by or potentially improved through the application of research on intrinsic and extrinsic aspirations.

My trepidations are somewhat balanced by my interest in the fact that certain US individuals and organisations have proposed legislative agendas that can be viewed through the lens of the research discussed above. That is, it seems to me that several extant legal proposals have the aim (intentionally or not) of increasing the opportunity for intrinsic pursuits and/or decreasing the likelihood that extrinsic goals and values continue their dominance in social functioning. Below, I attempt to demonstrate this synergy through the examination of two distinct sets of legislative proposals.

\section{A Time affluence}

Contemporary society, with its capitalist economic organisation dependent on consumer spending, places great emphasis on increasing material affluence as a barometer of progress. As we have seen, however, there are significant psychological, social, and ecological costs to organising one's life around the pursuit of the extrinsic goals embodied in material affluence. Further, research consistently shows that improvements in material affluence do not translate into improved subjective well-being, at least in economically developed nations. ${ }^{50}$ Clearly, then, we need other models of the good life to supplant that of material affluence.

Time affluence is one such model. Like money, time is scarce and limited by the facts that the day is 24 hours long, the year has 365.25 days, and each of us will eventually die. And the time available to us once we have finished the work we must do is becoming increasingly scarce, at least in my country. After years of being a leader in the movement to decrease work hours, ${ }^{51}$ annual work hours in the United States have increased from 1716 per year in 1967 to 1878 per year in $2000 .^{52}$ That's an extra four weeks of work per year. Further, compared to other economically developed nations, contemporary Americans work exceedingly long hours. For example, in 2000, Norwegians worked 1376 and the Dutch worked 1343 hours per year, ${ }^{53}$ despite having approximately the same wealth as Americans. These

\footnotetext{
${ }^{50}$ Diener \& Seligman, supra note 13 at $1-13$.

${ }^{5}$ Benjamin Hunnicutt, When we had the time, in TAKE BACK YOUR TIME: OvERwORK AND TIME POVERTY IN AMERICA 114-122 (John deGraaf ed., 2003).

52 Juliet Schor, The (Even More) Overworked American, in TAKE BACK YOUR TIME: FIGHTING OVERWORK AND TIME POVERTY IN AMERICA, 6-11 (John deGraaf ed., 2003).

${ }^{53}$ Anders Hayden, Europe's work-time alternatives, in TAKE BACK YOUR TIME: FIGHTING OVERWORK AND TIME POVERTY IN AMERICA, 202-210 (John deGraaf ed., 2003).
} 
differences translate into Americans working an additional 10 to 14 weeks per year, or an extra year of work every five years.

Although work certainly can have its intrinsic satisfactions, it is also heavily aimed towards the extrinsic aims of earning money and enhancing status. More importantly, as work hours increase, we by necessity have less time to devote to the intrinsic pursuits of developing as people, nurturing our families, and contributing to our communities. Each of these intrinsic pursuits requires time, but for many Americans, free time is exceedingly and unfortunately unavailable. As such, one excellent legal strategy for decreasing a culture's focus on extrinsic aims and increasing citizens' opportunities for intrinsic pursuits is to encourage people to maximise their time affluence and to provide them with more opportunities to do so.

A number of important strides towards this end have been taken by the group "Take Back Your Time," chaired by John deGraaf. ${ }^{54}$ In addition to holding a "national holiday" on October 24, 2003, publishing an edited book on the problems of time poverty, ${ }^{55}$ and building coalitions, the organisation recently developed a four-point legislative agenda designed to improve time affluence in the United States. ${ }^{56}$ My read of this agenda is that it also has the opportunity to encourage and support intrinsic rather than extrinsic aspirations.

The first legislative item on this agenda is to "Enact paid family leave" as "millions of poor Americans can't afford to utilise the Family and Medical Leave Act, which allows workers 12 weeks of unpaid leave to care for newborn children or sick relatives." The fact that the United States provides little in the way of paid leave is particularly staggering when we consider that 163 other nations do so. Of course, passing laws which support paid family leave would have the important effect of allowing individuals to pursue the intrinsic aspiration of affiliation, particularly in critical moments of transition in life (e.g., births and deaths).

The second proposition is to "Require three weeks minimum paid vacation for all workers." The typical American paid vacation is only two weeks, in comparison to the legal minimum of four weeks in European Union nations. What's more, many American workers, particularly low-income women, take no paid vacation at all. By passing laws that increase vacation time, individuals would have the opportunity to pursue their personal interests, spend time with their family, and actually pause and reflect on their life rather than continue the helter-skelter lifestyle so prominent in contemporary America. Such a law might be decried by those in business who concern themselves primarily with profit, but, as noted above, we must recognise that other aims in life besides money need to be supported by our legal mechanisms.

\footnotetext{
${ }^{54}$ see <www.timeday.org>

${ }^{55}$ TAKe Back Your Time: Fighting Overwork and Time Poverty in AMERICA, (John Degraff, ed., 1993).

${ }^{56}$ JOHN DEGRAAF, IT'S ELECTION SEASON AND THE ISSUE IS... OR SHOULD BE...TIME. TAKE BACK YOUR TIME NewSLETTER, (August 2004.)
} 
The third proposal, to "Give workers the right to refuse overtime after 48 hours on the job per week" would again bring the US in line with many other economically developed nations. Rather than being held hostage by employers who threaten the loss of job security and future raises if employees do not work more, workers would be able to be more in charge of their life (thus supporting personal growth aspirations), as well as potentially have more time to spend with friends and family (i.e., affiliation aspirations) and in civic and volunteer activities (i.e., community feeling).

Finally, deGraaf proposes that the U.S. should "Make Election Day a holiday." ${ }_{7}$ Voter turnouts for US citizens have generally been on the decline, despite the fact that the close elections of 2000 and 2004 showed the importance of every single vote. Were the nation to recognise that civic responsibilities (i.e., community feeling aspirations) need to be supported in the face of the press of work obligations (i.e., extrinsic pursuits), perhaps more individuals would take the time to become involved in this important aspect of democracy.

In sum, these four legislative proposals seem to hold great promise for improving "the good life" in the United States. Not only are they already in place in many other nations (including some much poorer than the US) but they could work to diminish the power of the extrinsic pursuits so dominant in our culture and to support the intrinsic aspirations which we know provide personal, social, and ecological well-being. Other legislative possibilities could also be developed (see for example Segal $^{58}$ ) that might have the dual benefit of increasing time affluence and intrinsic values while decreasing our national obsession with material affluence and extrinsic aspirations.

\section{B The commercialisation of childhood}

Capitalist markets must expand in order to satisfy their quest for ever-increasing profits, and in the last two decades, marketers have broken new ground by focusing on children and teens, who purchase or influence their parents' purchase of around $\$ 500$ billion annually worth of products and services. ${ }^{59}$ Not surprisingly, marketers have consequently spent a great deal of time, effort and money ( $\$ 12$ billion per year at the turn of the millennium; ${ }^{60}$ trying to influence children's desires for more stuff. Although some may claim that this is a natural and appropriate way to increase consumption and thus economic progress (i.e., extrinsic pursuits), there are good reasons to be uneasy about this development.

As has recently been well-documented in books by Linn $^{61}$ and Schor ${ }^{62}$ a great deal of evidence suggests that many of the messages and products which are marketed to

\footnotetext{
${ }^{57}$ Id.

58 Jerome Segal, A policy agenda for taking back time, in TAKE BACK YOUR TIME: FIGHTING OVERWORK AND TIME POVERTY IN AMERICA 211-218 (John. deGraaf ed., 2003)

${ }^{59}$ Packaged Facts, The Kids Market, available at <http://www.marketresearch.com> (March 2000).

${ }^{60}$ Faye Rice, Superstars' of spending; Marketers clamor for kids, ADVERTISING AGE, Feb. 12, 2004.

${ }^{61}$ SUSAN LINN, CONSUMING KIDS: THE HOSTILE TAKEOVER OF CHILDHOOD (2004).

62 Juliet Schor, Born to BuY: The COMMERCIAlised KID AND THE NEW CONSUMER Culture (2004).
} 
children are unhealthy in one way or another. These authors review evidence that when children consume consumer culture, they are placed at increased risk of developing eating disorders (both obesity and anorexia/bulimia), being violent and sexually promiscuous, feeling less happy, having more arguments with their families, and believing that materialistic values are important in life. Similar to my work on materialism in children, ${ }^{63}$ Schor $^{64}$ has found that children high in "consumer involvement" report more depression, anxiety, and physical symptoms, as well as lower self-esteem. Schor also finds that such children report more conflict with their parents.

Even though the data presented above suggest that marketing may also harm adults by inculcating a desire for extrinsic pursuits, there are special reasons to be particularly concerned about marketing to children. For one, children are often exposed to advertisements in schools; because attendance at school is compulsory, children are thus forced to see corporate banners in the hallways, study curricula sponsored by corporations, or even watch television shows such as Channel One that contain advertisements. ${ }^{65}$ Another problem concerns children's still-developing cognitive abilities. The American Psychological Association Task Force on Advertising and Children $(2004)^{66}$ recently concluded that children under age 8 have great difficulty understanding the persuasive intent of advertising. Thus, although older children and adults have the cognitive capacity to become aware of how advertisements are attempting to manipulate them and can understand the biases inherent in advertising, children (especially the very young) trust the messages they see in advertisements, and are thus at the mercy of those who create them.

It would be one thing if marketers had children's best interests at heart, but a quick read through the writings of Schor or Linn makes it clear that many marketers care little about the welfare of the children to whom they sell. ${ }^{67}$ Consider the following quote, for instance:

Advertising at its best is making people feel that without their product, you're a loser... Kids are very sensitive to that. If you tell them to buy something they are resistant, but if you tell them that they'll be a dork if they don't, you've got their attention. You open up emotional vulnerabilities, and it's very easy to do with kids because they're the most emotionally vulnerable. ${ }^{68}$

Given the research on extrinsic aspirations reviewed above, we should perhaps not be surprised that some marketers speak about children in this way. That is, people's extrinsic pursuits lead them to care less about others' welfare, be less empathic, and be more Machiavellian. It therefore makes perfect sense that many individuals who

\footnotetext{
${ }^{63}$ Tim Kasser, supra note 36 at 358-374.

${ }^{64}$ Schor, supra note 62.

${ }^{65}$ Linn, supra note 61 ; Schor, supra note 62.

${ }^{66}$ AMERICAN PSYCHOLOGICAL ASSOCIATION, PSYCHOLOGICAL ISSUES IN THE INCREASING COMMERCIALISATION OF CHILDHOOD (2004).

${ }^{67}$ Linn, supra note 61 ; Schor, supra note 62.

${ }^{68}$ Ron Harris, Children who dress for excess: Today's youngsters have become fixated with fashion. The right look isn't enough - it also has to be expensive, LOS ANGELES TIMES, Nov. 12, 1989.
} 
are interested in making money off of children are willing to manipulate children, sell them unhealthy products, and promote materialism and extrinsic pursuits.

Several legislative options to counteract marketing to children have been proposed by Linn and Schor, ${ }^{69}$ as well as by an organisation known as Commercial Alert, which has drafted a nine-point Parent's Bill of Rights. ${ }^{70}$ Although there is not space here to discuss the many possibilities for legislation, I would like to highlight four sets of proposals mentioned by these sources that could work to decrease the spread of extrinsic aspirations in children, as well as block the actions of those marketers so taken with extrinsic aspirations that they are willing to advertise harmful products and messages.

The first set of proposals concerns disclosure. Advertisements are increasingly hidden in television shows, movies, Internet pop-up ads, and even in chat rooms and everyday interactions where actors are hired to promote certain products without revealing that they are paid to do so. Clearly many of these methods involve intent to deceive, and the problem has become so extreme on some television shows (e.g., American Idol) that the program verges on being an undeclared programlength commercial. For this reason, Linn, Schor, and Commercial Alert (2003) $)^{71}$ all recommend mandates that would force marketers to clearly state when an advertisement is occurring. Further, these statements would need to be made in ways that are age-appropriate, i.e., so even young children exposed to advertisements know that an advertisement is occurring. Such a set of legislative proposals would help decrease much of the unconscious conditioning by which marketers promote their products and extrinsic pursuits.

A second set of suggestions from both Schor and Linn ${ }^{72}$ is to create legislation that would make marketing research subject to the same stringent ethical review processes that are required for any work done in academic settings. Currently, marketers conducting research operate under none of the current regulations, which require them to obtain subject consent, protect minors, or notify subjects of the potential harm from participating in the research. Given the evidence that marketers often sell products that are harmful, and that they have even conducted studies designed to better understand how children successfully nag their parents to buy certain products, ${ }^{73}$ it is important to force marketers to operate under the same ethical standards for research as occurs in other research settings.

Third, tax laws could be reformed to decrease the benefits of advertising to children. One approach to tax legislation has been proposed by Commercial Alert, ${ }^{74}$ who suggests that Congress end the practice of allowing corporations to deduct

\footnotetext{
${ }^{69}$ Linn, supra note 61; Schor, supra note 62.

${ }^{70}$ Commercial Alert, Commercial Alert's Parents' Bill of Rights,

$<$ http://www.commercialalert.org/pbor.pdf > (2003).

${ }^{71}$ Linn, supra note 61, Schor, supra note 62, Commercial Alert, supra note 70.

${ }^{72}$ Linn, supra note 61 , Schor, supra note 62.

${ }^{73}$ Western Media International, The fine art of whining: Why nagging is kid's best friend, BuSINESS WIRE, Aug. 11, 1998.

${ }^{74}$ Commercial Alert, supra note 70
} 
advertising expenses. Another approach suggested by Schor and by Linn ${ }^{75}$ is to levy a tax on advertising which is aimed at audiences with high proportions of children and teenagers. The money raised from such taxes could then be devoted to commercial-free public television, to media literacy campaigns, or even to programs designed to increase what I would call intrinsic aspirations. Changes in such tax laws hit extrinsically oriented marketers where it hurts the most (i.e., the pocketbook) and could thus be quite effective.

Finally, outright bans on marketing in certain situations, marketing of certain products, marketing in certain ways, and marketing to children under certain ages have been proposed by Linn, Schor, and Commercial Alert (2003). ${ }^{76}$ All agree that most marketing in schools or on school property (including school buses) should be outlawed, given that it is inescapable. Schor and Linn ${ }^{77}$ have both suggested following the lead of New Zealand by banning all advertisements of junk food. Linn also suggests banning advertisements that demean adults, or that suggest that ownership of a certain product will promote peer acceptance. ${ }^{78}$ Finally, all agree that nations concerned about the welfare of children should consider following the lead of Sweden, Norway, Finland and the Canadian province of Quebec by banning altogether advertisements to children under certain ages, although disagreement exists about whether the appropriate age is 5,8 , or 12 years old.

\section{CONCLUSION}

My hope is that the research reviewed early in the first half of this article suggests to lawyers a variety of ways that they could modify the legal system to enhance individuals' opportunities to attain "the good life." I hope I have made clear that many features of contemporary, consumeristic, hyper-capitalistic society stand in the way of this worthy aim, and that what is necessary is to fashion a culture which does a better job of encouraging and providing opportunities for individuals to pursue the intrinsic aspirations which research shows facilitate personal happiness, social justice, and ecological sustainability.

In addition to legislative agendas aimed at maximising time affluence and minimising the commercialisation of childhood, I believe that the lens of intrinsic and extrinsic aspirations can be fruitfully applied to a variety of other topics. For example, Sheldon \& Krieger ${ }^{79}$ have documented how law school may shift students' concerns from intrinsic to extrinsic; certainly the pedagogical practices which may be causing this unfortunate occurrence could be reviewed and addressed. Further, the writings of individuals like Korten ${ }^{80}$ and Kelly ${ }^{81}$ on economic democracy and

\footnotetext{
${ }^{75}$ Linn, supra note 61, Schor, supra note 62.

${ }^{76}$ Linn, supra note 61, Schor, supra note 62, Commercial Alert, supra note 70.

${ }^{77}$ Linn, supra note 61 , Schor, supra note 62.

${ }^{78}$ Linn, supra note 61.

${ }^{79}$ Sheldon, et. al, supra note 22.

${ }^{80}$ DAVID KorTen, THE POST-CORPORATE WORLD: LifE AFTER CAPITALiSM, (1999), DAVID KorTON, WHEN CORPORATIONS RULE THE WORLD, (2d, 2001).
} 
corporate responsibility provide a host of suggestions for corporate law that might work to support intrinsic and discourage extrinsic aims. Lawyers interested in city planning might also examine how current development laws promote extrinsic pursuits and block potential community options that could improve happiness and social cohesion, and that could decrease a city's ecological footprint (see <www.smartgrowthonline.org>). In sum, there are a variety of legislative proposals that could keep busy a slew of lawyers interested in promoting intrinsic and discouraging extrinsic values, and of thus using the law as a way to bring about "the good life."

\footnotetext{
${ }^{81}$ Marjorie Kelly, The Divine Right of Capital: Dethroning the Corporate Aristocracy,
} (2001). 